\title{
Application of ejectors for two-phase flows
}

\author{
Liudmila Volgina* and Anastasiia Romanova
}

Moscow State University of Civil Engineering, Yaroslavskoe shosse, 26, Moscow, 129337, Russia

\begin{abstract}
The article studies the work of a water jet pump (ejector), influence of the mixture characteristics and pipe length on the energy parameters of the ejector system. The relevance of the topic is associated with the active use of ejectors in the modern world in various areas, including in hydraulic structures. Frequent use of ejectors is ensured by high reliability, simplicity of design and maintenance. The purpose of this work is to study the operation of the ejector, the energy characteristics of the flow and the influence of the characteristics of the transported two-phase flow. The calculation of the real practical problem of selecting an ejector for lifting and transporting solid particles is given. The values of the density of the transported mixture and the length of the transport pipes are selected as variable indicators. The analysis of the calculation shows that taking into account the energy characteristics of the flow when selecting the components of the ejector system is very important, and the density of the transported mixture affects the efficiency of the system.
\end{abstract}

\section{Introduction}

We can often detect the silting of the bottom during the operation of hydrotechnical constructions, in reservoirs and other water structures with stagnant or slow-flowing water. Siltation is a concentration of bed load caused by solid particles of clastic material, which is dominated by silt, sand or clay particles. This effect has a negative impact on exploitation of hydrotechnical constructions [1,2]. It is a problem.

There are several ways to solve the problem:

1. Make a salvo release of water. It is very important to provide hydraulic washing with a fast increase in discharge determined only by the opening time of the valves of the regulating hydrotechnical structure (usually 10-15 minutes). Under such conditions, the disturbance wave will spread quickly in the channel. It leads to a fast increase in the flow velocity and intensive erosion of bed load.

2. Lift the particles from the bottom with the ejector. When calculating the effectiveness of this method, it is necessary to choose the velocity and type of movement of the liquid (energetically favorable) [3].

A similar problem was considered by the Moscow State University of Civil Engineering (MGSU). As part of the canal reconstruction project, they carried out a study on the topic "Hydraulic efficiency of engineering measures to increase the transit discharge of the Moscow Canal".

\footnotetext{
* Corresponding author: VolginaLV@mgsu.ru
} 
For the study, depth measurements were carried out along the overpass in the lower reservoir from the side of the supplying channel. Last year depth measurements made at the same points showed that the sediment level had changed. The passage section under the overpass has decreased compared to past measurements. Solid particles impair the operation of structures (the wave mode of the trunk channel is changing, the passage section under the overpass is reduced, the operation of the pumping equipment deteriorates and turbidity is increased).

No doubt, it is essentially needed to clean the supplying channel from bed load. The work on clearing the channel is required to be systematic, because sedimentation happens all the time.

MGSU (MISI) proposed one of the hydraulic ways to clean the supply channel, which does not require energy and water consumption. This method is simple in design and is based on the use of ejector. The raised sediments can be stored in the riverside zone or removed outside the structure.

\subsection{Application of ejectors in modern world}

The ejector works according to Bernoulli's equation. It creates a reduced pressure of one environment medium in the narrowing cross-section, which creates a suction into the flow of another environment medium. This mechanism is quite common in the modern world. The scope of application of ejectors is also very large: pumping out dangerous gases, ventilation of enclosed spaces, transport of coal dust, ash, cement, wood chips, grain, sugar, milk powder. Ejectors are used in cars. One of the most popular choices options for reagent-free water treatment systems is ejection. $[4,5,6]$

The advantages of ejectors are: no moving parts, easy maintenance, high reliability and simple design, low operating cost.

\section{Methods}

\subsection{General information about water jet pumps (ejectors)}

The general installation diagram of the water jet pump is shown on Fig. 1. Through the pressure line (1) working flow with work discharge flow $\mathrm{Q}_{1}$ is brought to the mixing chamber (2) of ejector. Specified discharge flow $\mathrm{Q}_{2}$ is brought from the lower reservoir through a suction pipe (3) in mixing chamber. Combined flow through a common water pipe (4) enters the upper reservoir $[7,8]$.

Ejector (Fig. 2) consists of a flow mixing chamber $\mathrm{Q}_{1}$ and $\mathrm{Q}_{2}(1)$, nozzle (2) which ends the pressure water pipe of the working flow at the entrance to the mixing chamber, suction pipe bend (3), which connects the suction pipe to the mixing chamber $[9,10]$.

The mixing chamber is usually cylindrical in shape (Fig. 2) with diameter $\mathrm{D}_{3}$ approximately equal to the sum of diameters (suction pipe and nozzle diameters).

The mixing chamber is attached to the diffuser and it is connected to the water pipe to supply the receiving reservoir. 


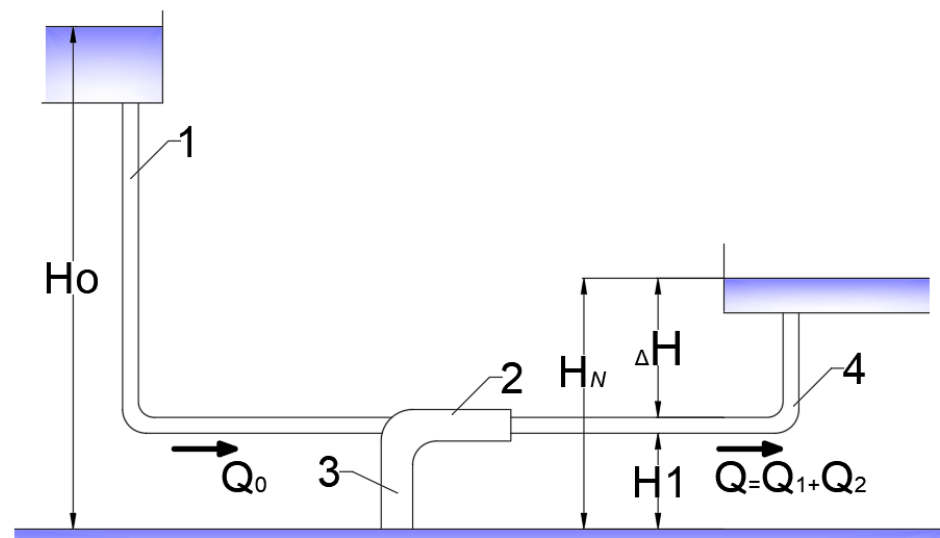

Fig. 1. Diagram of ejector

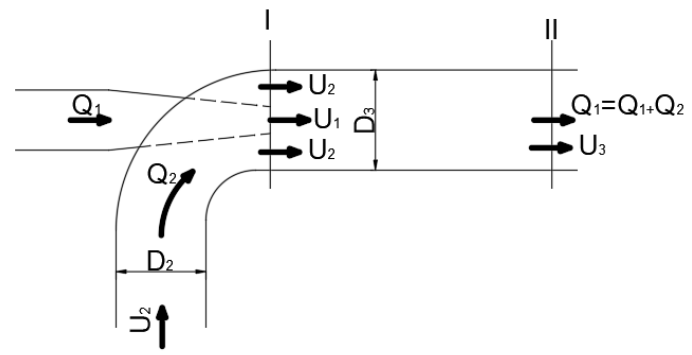

Fig. 2. Diagram of the flow mixing in ejector

The diagram of work ejector (Fig. 3) shows that when work discharge flow $\mathrm{Q}_{1}$ enters the mixing chamber through the nozzle with a high velocity, which creates a vacuum in side. With the aid of a vacuum, the water comes from the lower reservoir and enters the mixing chamber with a discharge flow $\mathrm{Q}_{2}[11]$.

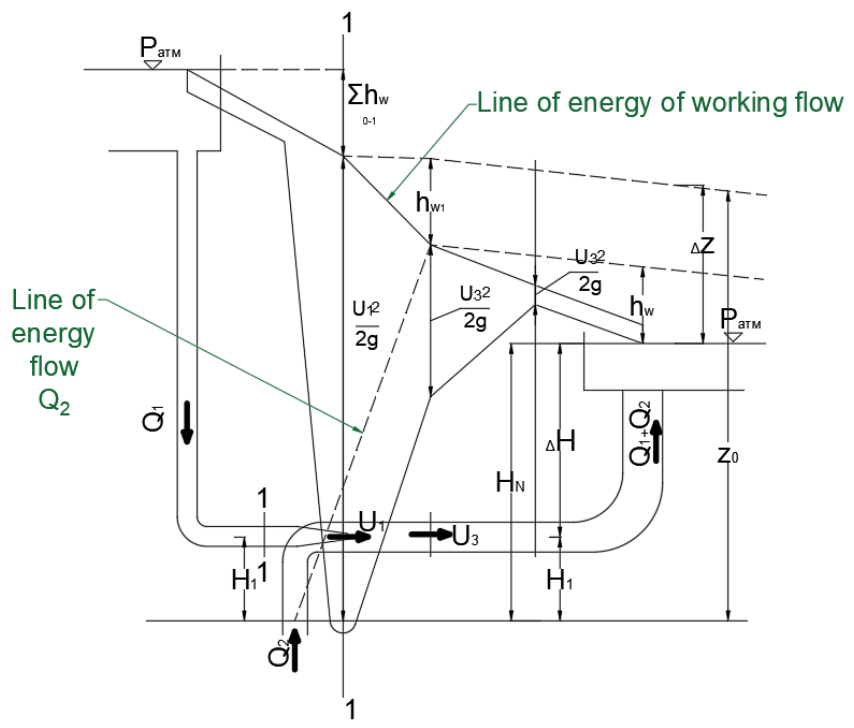

Fig. 3. Energy scheme 
Kinetic energy of the flow (formula 1):

$$
\rho g Q_{1} \frac{U_{1}^{2}}{2 g}
$$

Kinetic energy is more than the energy of the useful flow (flow from the lower reservoir to the upper one with a discharge of useful discharge flow $\mathrm{Q}_{2}$ ), which is equal to (formula 2):

$$
\rho g Q_{2} \frac{U_{2}^{2}}{2 g}
$$

When mixing flows, the velocity of the working flow $\mathrm{U}_{1}$ decreases to $\mathrm{U}_{3}$, and the velocity of the useful flow $U_{2}$ increases to the velocity of $U_{3}$ (formula 3 ). $U_{3}$-total average velocity of the mixed flow at the nozzle.

$$
U_{3}=\frac{Q_{1}+Q_{2}}{\omega_{1}+\omega_{2}}
$$

With this velocity of $U_{3}$, the mixed flow enters the diffuser.

\subsection{Energy calculation}

The energy required to lift the mass of the useful discharge flow $\mathrm{Q}_{2}$ from the lower level to the height of the upper receiving reservoir consists of energy:

a) to lift the specified useful discharge flow $\mathrm{Q}_{2}$ from the level of the lower reservoir to the height of the mixing chamber $\mathrm{H}_{1}$ (with resistance in the suction pipe) [12]:

$$
E_{2}=\rho g Q_{2}\left(H_{1}+\left(1+\xi_{l c}\right) \frac{U_{2}^{2}}{2 g}\right),
$$

where $\mathrm{U}_{2}$ - estimated flow velocity in the suction pipe; $\xi_{l c}$ - the total coefficient of resistance in this pipe.

b) to overcome hydraulic resistances in the mixing chamber (formula 5):

$$
E_{\mathrm{cm}}=\rho g\left[Q_{1}+Q_{2}\right] h_{w}
$$

where $h_{w}-$ lost pressure on mixing flows;

c) to raise the total flow velosity to a height of $\Delta \mathrm{H}$ (from the level of the mixing chamber to the level of the free surface of the water in the receiving reservoir $\left.\Delta \mathrm{H}=\mathrm{H}_{2}-\mathrm{H}_{1}\right)$, and also to overcome all the hydraulic resistances along the way:

$$
E_{N}=\rho g\left(Q_{1}+Q_{2}\right)\left(\Delta H+\left(\xi_{\mathrm{d}}+\lambda \frac{l}{D_{4}}+1\right) \frac{U_{4}^{2}}{2 g}\right),
$$

where $\xi_{\mathrm{d}}$ - the coefficient of resistance of the in diffuser.

So the total energy consumption is determined as

$$
E_{\text {полн }}=E_{2}+E_{\text {см }}+E_{N} \text {, }
$$

The working flow should have exactly this energy at the entrance to the mixing chamber.

\section{Results}

Consider the basic scheme of a water jet installation (Fig. 1). Take into account the difference in the total energy reserve of the entire flow in the initial I and final II cross-sections of the mixing chamber. Obviously, the difference between these energies is the loss of energy of the entire combined flow within the chamber. This loss consists of the loss of energy to move the flow along the length of the chamber and the loss of energy to realize the process of mixing the two flows. The first type loss of energy can be ignored. It is very small compared to the mixing energy. $[13,14,15]$

Full energy reserve in the first cross-section we define as the sum of the energy the working flow (with the discharge $\mathrm{Q}_{1}$ ) and the energy of the useful flow (with the discharge $\mathrm{Q}_{2}$ ). 
- For cross-section $I$

- For cross-section II

$$
\begin{gathered}
E_{1}=\rho g Q_{1}\left(\frac{P_{1}}{\rho g}+\frac{U_{1}^{2}}{2 g}\right)+\rho g Q_{2}\left(\frac{P_{2}}{\rho g}+\frac{U_{2}^{2}}{2 g}\right)= \\
\rho g\left(Q_{1}+Q_{2}\right) \frac{P_{1}}{\rho g}+\rho g Q_{1} \frac{U_{1}^{2}}{2 g}+\rho g Q_{2} \frac{U_{2}^{2}}{2 g}
\end{gathered}
$$

$$
E_{2}=\rho g\left(Q_{1}+Q_{2}\right)\left(\frac{P_{3}}{\rho g}+\frac{U_{3}^{2}}{2 g}\right)
$$

Therefore, the loss of energy in the mixing chamber:

$$
\begin{gathered}
\Delta E_{n}=E_{1}-E_{2}= \\
\rho g\left(Q_{1}+Q_{2}\right)\left(\frac{P_{1}}{\rho g}-\frac{P_{3}}{\rho g}\right)+\rho g Q_{1} \frac{U_{1}^{2}-U_{3}^{2}}{2 g}+\rho g Q_{2} \frac{U_{2}^{2}-U_{3}^{2}}{2 g}
\end{gathered}
$$

or (because $\mathrm{Q}_{1}+\mathrm{Q}_{2}=\mathrm{Q}$ ):

$$
\Delta E_{n}=\rho g Q \frac{P_{1}-P_{3}}{\rho g}+\rho g Q_{1} \frac{U_{1}^{2}}{2 g}+\rho g Q_{2} \frac{U_{2}^{2}}{2 g},
$$

Note that only the working flow $\mathrm{Q}_{1}$ consumes energy, and the useful flow $\mathrm{Q}_{2}$ even increases it. So energy consumption can be written as:

$$
\Delta E_{n}=\rho g Q h_{w 1}
$$

where $\mathrm{h}_{\mathrm{w} 1}-$ specific lost pressure of the working flow

$$
h_{w 1}=\frac{\Delta E_{n}}{\rho g Q_{1}},
$$

If formula (11a) is substituted into formula (11), then

$$
\rho g Q_{1} h_{w 1}=\rho g Q \frac{P_{1}-P_{3}}{\rho g}+\rho g Q_{1} \frac{U_{1}^{2}-U_{3}^{2}}{2 g}+\rho g Q_{2} \frac{U_{2}^{2}-U_{3}^{2}}{2 g}
$$

or, dividing by $\rho g Q_{1}$, we determine the value of the lost discharge (so the lost energy attributed to the unit weight of the working flow discharge:

$$
h_{w 1}=\frac{\mathrm{Q}}{Q_{1}} \cdot \frac{P_{1}-P_{3}}{\rho g}+\frac{U_{1}^{2}-U_{3}^{2}}{2 g}+\frac{Q_{2}}{Q_{1}} \cdot \frac{U_{2}^{2}-U_{3}^{2}}{2 g},
$$

In formula (13), the unknowns are $\mathrm{Q}_{1}, \mathrm{U}_{1}, \mathrm{P}_{3}$ and $\mathrm{U}_{3}$.

Note that $h_{w l}$ is the specific energy lost by the working flow (not the entire flow), since

$$
h_{w 1}=\frac{\Delta E_{n}}{\rho g Q}
$$

Here all the lost energy is related to the unit weight of the working flow.

If attribute this lost energy to the unit weight of the entire flow, get

Obviously, $h_{w 1}>h_{w}$

$$
h_{w}=\frac{\Delta E_{n}}{\rho g Q_{1}}=\frac{\Delta E_{n 1}}{\rho g\left(Q_{1}+Q_{2}\right)}
$$

Let's determine the value $h_{w 1}$ in a different way, using the formula of change in the amount of motion, that is, the equation of momentum. The calculation scheme is shown in Fig. 4.

The length of the mixing chamber is determined using the data of experimental studies on the expansion of the jet (for example, if the expansion at an angle of $\alpha^{\circ}=15^{\circ}$ ), and then

$$
l=\frac{D_{3}}{2 \lg \alpha} \approx(4-5) D_{3}
$$

Let's make an equation of the change in the amount of motion for the mass of a liquid enclosed in a cylindrical mixing chamber with a diameter of

$$
\begin{aligned}
D_{3} & \cong D_{2}+d_{2} ; \\
\Delta(m V) & =\sum P \cos \alpha d t
\end{aligned}
$$




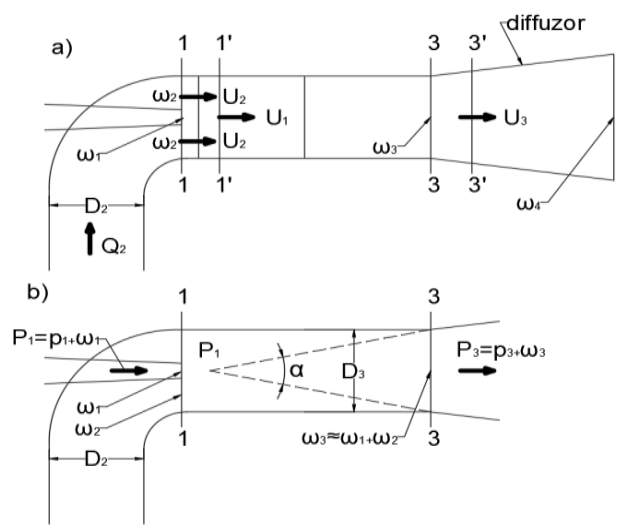

Fig. 4. Diagram for the impulse equation

During the time $d t$, this mass will move to the position (1'-1') - (3'-3') (Fig. 4,a).

Note that under steady motion conditions, the amount of mass motion in the region between sections ( $\left(1^{\prime}-1^{\prime}\right)$ and (3-3) does not change.

Therefore, it can be determined the increment of the movement of the allocated mass as follows:

$$
\begin{array}{r}
\Delta(m V)=\rho \alpha_{0} d t \omega_{3} U_{3}^{2}-\rho \alpha_{0} d t\left(\omega_{1} U_{1}^{2}-\omega_{2} U_{2}^{2}\right) \\
=\rho \alpha_{0} d t\left(\omega_{3} U_{3}^{2}-\omega_{1} U_{1}^{2}-\omega_{2} U_{2}^{2}\right)
\end{array}
$$

Below is a formula for determining the sum of the impulses of external forces acting on the above-mentioned mass of liquid:

$$
\sum \mathrm{p} \cos \alpha d t=\left(p_{1}-p_{2}\right) d t
$$

The gravity (weight) and the pressure forces of the walls of the mixing chamber are normal to the axis of motion and the projection of their impulses is zero. The forces $p_{1}$ and $p_{2}$ are equal to (Fig. 4.b)

$p_{1}=P_{1} \omega_{3}$ и $p_{2}=P_{3} \omega_{3}$ Therefore, the sum of the impulses is equal to

$$
\sum \mathrm{p} \cos \alpha d t=\left(P_{1}-P_{3}\right) \omega_{3} d t
$$

All equations of change in the amount of movement are written as follows:

$$
\rho \alpha_{0} d t\left(\omega_{3} U_{3}^{2}-\omega_{1} U_{1}^{2}-\omega_{2} U_{2}^{2}\right)=\omega_{3}\left(P_{1}-P_{3}\right) d t
$$

We transform this equation by dividing both parts by $\rho g d t$, and multiply by $U_{3}$. Turn out: if $\alpha_{0}=1.0$, than

$$
\frac{U_{3} \omega_{3} U_{3}^{2}}{g}-\frac{U_{3} \omega_{1} U_{1}^{2}}{g}-\frac{U_{3} \omega_{2} U_{2}^{2}}{g}=\frac{P_{1}-P_{3}}{\rho g} \omega_{3} U_{3}
$$

Because $U_{3} \omega_{3}=Q ; \quad U_{3} \omega_{3} U_{1}^{2}=U_{3} U_{1} \omega_{3} U_{1}=U_{3} U_{1} Q_{1} \quad$ и $U_{3} \omega_{2} U_{2}^{2}=U_{3} U_{2} Q_{2}$, the formula is obtained

but so as

$$
Q \frac{U_{3}^{2}}{g}-Q_{1} \frac{U_{3} U_{1}}{g}-Q_{2} \frac{U_{3} U_{2}}{g}=Q \frac{P_{2}-P_{3}}{\rho g},
$$

$$
Q \frac{U_{3}^{2}}{g}=\left(Q_{1}+Q_{2}\right) \frac{U_{3}^{2}}{g}=Q_{1} \frac{U_{3}^{2}}{g}+Q_{2} \frac{U_{3}^{2}}{g},
$$

then, making a substitution in (10) turned out

$$
Q_{1} \frac{U_{3}^{2}-U_{3} U_{1}}{g}+Q_{2} \frac{U_{3}^{2}-U_{3} U_{2}}{g}=Q \frac{P_{2}-P_{3}}{\rho g},
$$

The binomial $(a-b)^{2}$ can be converted as:

Where from:

$$
(a-b)^{2}=a^{2}-2 a b+b^{2}+a^{2}-a^{2}=2\left(a^{2}-a b\right)+b^{2}-a^{2}
$$


Using this the formula has the form:

$$
\left(\mathrm{a}^{2}-\mathrm{ab}\right)=\frac{(a-b)^{2}}{2}+\frac{a^{2}-b^{2}}{2}
$$

$$
U_{3}^{2}-U_{3} U_{1}=\frac{\left(U_{3}-U_{1}\right)^{2}}{2}+\frac{U_{3}^{2}-U_{1}^{2}}{2}
$$

and

$$
U_{3}^{2}-U_{3} U_{2}=\frac{\left(U_{3}-U_{2}\right)^{2}}{2}+\frac{U_{3}^{2}-U_{2}^{2}}{2}
$$

Substituting these expressions in the equation (27) and dividing $Q_{1}$ resulted in:

$$
\frac{Q}{Q_{1}} \cdot \frac{P_{1}-P_{3}}{\rho g}=\frac{\left(U_{3}-U_{1}\right)^{2}}{2 g}+\frac{U_{3}^{2}-U_{1}^{2}}{2 g}+\frac{Q_{2}}{Q_{1}} \cdot \frac{\left(U_{3}-U_{2}\right)^{2}}{2 g}+\frac{Q_{2}}{Q_{1}} \cdot \frac{U_{3}^{2}-U_{2}^{2}}{2 g}
$$

Let's rewrite this equality differently:

$$
\frac{Q}{Q_{1}} \cdot \frac{P_{1}-P_{3}}{\rho g}+\frac{U_{1}^{2}-U_{3}^{2}}{2 g}+\frac{Q_{2}}{Q_{1}} \cdot \frac{U_{2}^{2}-U_{3}^{2}}{2 g}=\frac{\left(U_{3}-U_{1}\right)^{2}}{2 g}+\frac{Q_{2}}{Q_{1}} \cdot \frac{\left(U_{2}-U_{3}\right)^{2}}{2 g}
$$

The left part of formula (33) represents the lost pressure for the working flow, i.e. the value $h_{w l}$ from formula (14). Therefore, the right part represents the same value.

So, the second formula for $h_{w 1}$ is written below:

$$
h_{w}=\frac{\left(U_{3}-U_{1}\right)^{2}}{2 g}+\frac{Q_{2}}{Q_{1}} \cdot \frac{\left(U_{2}-U_{3}\right)^{2}}{2 g} .
$$

Using this formula, determines the amount of energy consumed by the working flow in the mixing chamber:

$$
\mathrm{E}_{\mathrm{cM}}=\rho g Q_{1} h_{w 1}=\rho g Q_{1} \cdot \frac{\left(U_{3}-U_{1}\right)^{2}}{2 g}+\rho g Q_{2} \cdot \frac{\left(U_{2}-U_{3}\right)^{2}}{2 g} .
$$

The formula (35) in a slightly different form was also obtained by Zeiner in 1873.

\section{Discussion}

Based on the data obtained during the inspection of the channel, will be evaluate the effects of the consistency, pressure loss and length of the ejector pipes on the working flow velocity.

The calculations are made in the following order of determining the values (Fig. 5):

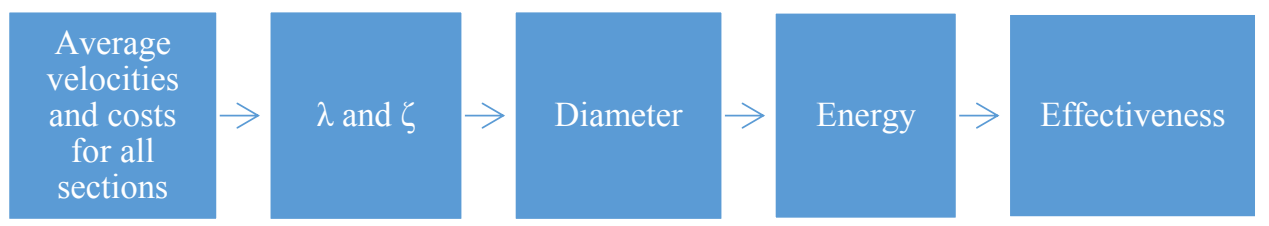

Fig. 5. The procedure for calculating

The specific gravity $\gamma$ (from 1 to 1.3 in increments of 0.2 ) of the mixture is used to determine the work discharge flow $\mathrm{Q}_{1}$. [16]

The diameter of the nozzle exits hole $d$ and the diameter of the mixing chamber $\mathrm{D}_{3}$ are determined by the formulas (36).

$$
d=\sqrt{\frac{4 Q_{1}}{0.9 \pi \sqrt{2 g \Delta H}}}
$$

We determine the coefficient $\zeta_{\mathrm{d}}$ by the formula (38):

Where $\mathrm{K}_{p r}=0,14$,

$$
\zeta_{d}=\kappa_{p r}\left(\frac{\omega_{4}}{\omega_{3}}-1\right)^{2}
$$


The initial data for the calculation of the practical problem is presented in the tabular form (Table 1).

Table 1. Initial data

\begin{tabular}{|c|c|}
\hline Name & Value \\
\hline $\mathrm{D}_{1}$ & $0,1 \mathrm{~m}$ \\
\hline $\mathrm{D}_{2}$ & $0,1 \mathrm{~m}$ \\
\hline $\mathrm{D}_{4}$ & $0,15 \mathrm{~m}$ \\
\hline $\mathrm{U}_{2}$ & $2 \mathrm{~m} / \mathrm{s}$ \\
\hline $\mathrm{H}_{\mathrm{N}}$ & $3,5 \mathrm{~m}$ \\
\hline$\Delta \mathrm{H}$ & $8 \mathrm{~m}$ \\
\hline$\zeta$ & 6 \\
\hline $\mathrm{L}_{4}$ & $10 \mathrm{~m}$ \\
\hline $\mathrm{L}_{4}{ }^{\prime}$ & $100 \mathrm{~m}$ \\
\hline $\mathrm{g}$ & $9,81 \mathrm{~m} / \mathrm{s}^{2}$ \\
\hline $\mathrm{Re}$ & 200000 \\
\hline$\lambda$ & 0,0168 \\
\hline$\rho$ & $1 \mathrm{~g} / \mathrm{cm}^{3}$ \\
\hline
\end{tabular}

The definitions of discharge, diameters, and the coefficient $\zeta_{\mathrm{d}}$ are presented in tabular form (Table 2):

Table 2. Calculation of discharge, diameters, and the coefficient

\begin{tabular}{|c|c|c|c|c|c|c|c|c|c|c|c|}
\hline $\mathrm{Q}_{2}$ & $\gamma$ & $\mathrm{Q}_{1}$ & $\begin{array}{c}\mathrm{Q}= \\
\mathrm{Q}_{1}+\mathrm{Q}_{2}\end{array}$ & $\mathrm{U}_{1} *$ & d & $\mathrm{D}_{3}$ & $\omega_{3}$ & $\mathrm{~K}_{\text {пр }}$ & $\mathrm{D}_{4}$ & $\omega_{4}$ & $\zeta_{\text {д }}$ \\
\hline \multirow{14}{*}{$\begin{array}{l}\hat{n} \\
0 \\
0\end{array}$} & 1 & 0,0157 & 0,0314 & 2,0000 & 0,042 & 0,142 & 0,0159 & \multirow{14}{*}{$\frac{ \pm}{0}$} & 0,108 & 0,009137 & 0,122 \\
\hline & 1,06 & 0,0148 & 0,0305 & 1,8868 & 0,041 & 0,141 & 0,0156 & & 0,109 & 0,009343 & 0,111 \\
\hline & 1,08 & 0,0145 & 0,0302 & 1,8519 & 0,041 & 0,141 & 0,0155 & & 0,109 & 0,009408 & 0,108 \\
\hline & 1,1 & 0,0143 & 0,0300 & 1,8182 & 0,040 & 0,140 & 0,0154 & & 0,110 & 0,009472 & 0,105 \\
\hline & 1,12 & 0,0140 & 0,0297 & 1,7857 & 0,040 & 0,140 & 0,0153 & & 0,110 & 0,009534 & 0,102 \\
\hline & 1,14 & 0,0138 & 0,0295 & 1,7544 & 0,039 & 0,139 & 0,0153 & & 0,111 & 0,009595 & 0,099 \\
\hline & 1,16 & 0,0135 & 0,0292 & 1,7241 & 0,039 & 0,139 & 0,0152 & & 0,111 & 0,009654 & 0,096 \\
\hline & 1,18 & 0,0133 & 0,0290 & 1,6949 & 0,039 & 0,139 & 0,0151 & & 0,111 & 0,009712 & 0,094 \\
\hline & 1,2 & 0,0131 & 0,0288 & 1,6667 & 0,038 & 0,138 & 0,0150 & & 0,112 & 0,009769 & 0,091 \\
\hline & 1,22 & 0,0129 & 0,0286 & 1,6393 & 0,038 & 0,138 & 0,0150 & & 0,112 & 0,009824 & 0,089 \\
\hline & 1,24 & 0,0127 & 0,0284 & 1,6129 & 0,038 & 0,138 & 0,0149 & & 0,112 & 0,009878 & 0,087 \\
\hline & 1,26 & 0,0125 & 0,0282 & 1,5873 & 0,038 & 0,138 & 0,0148 & & 0,112 & 0,009932 & 0,085 \\
\hline & 1,28 & 0,0123 & 0,0280 & 1,5625 & 0,037 & 0,137 & 0,0148 & & 0,113 & 0,009984 & 0,083 \\
\hline & 1,3 & 0,0121 & 0,0278 & 1,5385 & 0,037 & 0,137 & 0,0147 & & 0,113 & 0,010035 & 0,081 \\
\hline
\end{tabular}

To calculate the required working flow velocity at the entrance to the mixing chamber, we use the formula (39):

$$
\frac{U_{1}{ }^{2}}{2 g}=\frac{Q_{2}}{Q_{1}} H_{N}+\Delta H+\frac{Q_{2}}{Q_{1}}\left(1+\xi_{c}\right) \frac{U_{2}^{2}}{2 g}+h_{w}+\frac{Q_{2}}{Q_{1}}\left(1+\xi_{\text {I }}+\lambda \frac{L}{D_{4}}\right) \frac{U_{4}{ }^{2}}{2 g}
$$

Each component of this formula (39) is indicated by a Roman numeral and color and corresponds to the same columns in the Table 3. The calculation uses $\mathrm{L}_{4}$ and $\mathrm{L}_{4}{ }^{\prime}-$ this is the length of the total water pipe from the mixing chamber to the upper reservoir. This length allows to see how the required velocity of the working flow changes.

To analyze the efficiency of the work, we use the efficiency factor. The efficiency factor is the proportion of the work required to the work expended. [17] The required work for lifting the liquid is determined by the formula (40):

$$
\mathrm{A}=\rho g Q_{2} H_{N}
$$


The real work is equal to (41):

$$
A_{1}=\rho g Q_{1} \Delta z
$$

where $\Delta \mathrm{z}$ is the difference between the working flow at the entrance to the mixing chamber and the lifting height of the useful discharge flow and atmospheric pressure. It can be defined as (42):

$$
\Delta z=\frac{U_{1}^{2}}{2 g}-h_{\text {вак }}-\Delta H
$$

The efficiency can be determined by the formula (43):

$$
\eta=\frac{A}{A_{1}}=\frac{Q_{2} H_{N}}{Q_{1}\left(\frac{U_{1}{ }^{2}}{2 g}-h_{\text {вак }}-\Delta H\right)}
$$

When selecting the pump required for the selected situation, use the formula (44):

$$
N=\frac{\rho \Pi Q_{2} \Delta H}{\eta}
$$

\begin{tabular}{|c|c|c|c|c|c|c|c|c|c|c|c|c|}
\hline \multirow[t]{2}{*}{ I } & \multirow{2}{*}{$\begin{array}{l}\mathrm{II}= \\
\mathrm{H}_{\mathrm{N}}\end{array}$} & \multirow[t]{2}{*}{ III } & \multirow[t]{2}{*}{ IV } & \multirow[t]{2}{*}{$\mathrm{U}_{4}$} & \multicolumn{3}{|c|}{$\mathrm{L}_{4}=10 \mathrm{~m}$} & \multicolumn{3}{|c|}{$\mathrm{L}_{4}{ }^{\prime}=100 \mathrm{~m}$} & \multirow[t]{2}{*}{$\eta$} & \multirow[t]{2}{*}{$\mathrm{N}$} \\
\hline & & & & & $\mathrm{V}$ & $\mathrm{U}_{1}^{2} / 2 \mathrm{~g}$ & $\mathrm{U}_{1}$ & $\mathrm{~V}$ & $\mathrm{U}_{1}^{2} / 2 \mathrm{~g}$ & $\mathrm{U}_{1}{ }^{\prime}$ & & \\
\hline 3,50 & \multirow{14}{*}{$m$} & 1,427115 & 0,000039 & 1,78 & 0,721 & 9,15 & 13,40 & 3,961 & 12,39 & 15,59 & 0,778 & 1,6 \\
\hline 3,71 & & 1,512742 & 0,000256 & 1,73 & 0,702 & 9,42 & 13,60 & 3,852 & 12,57 & 15,71 & 0,824 & 1,5 \\
\hline 3,78 & & 1,541284 & 0,000496 & 1,71 & 0,696 & 9,52 & 13,67 & 3,820 & 12,64 & 15,75 & 0,840 & 1,5 \\
\hline 3,85 & & 1,569827 & 0,000803 & 1,70 & 0,690 & 9,61 & 13,73 & 3,789 & 12,71 & 15,79 & 0,856 & 1,4 \\
\hline 3,92 & & 1,598369 & 0,001169 & 1,68 & 0,685 & 9,70 & 13,80 & 3,761 & 12,78 & 15,83 & 0,871 & 1,4 \\
\hline 3,99 & & 1,626911 & 0,001586 & 1,67 & 0,680 & 9,80 & 13,87 & 3,733 & 12,85 & 15,88 & 0,887 & 1,4 \\
\hline 4,06 & & 1,655454 & 0,002049 & 1,66 & 0,675 & 9,89 & 13,93 & 3,708 & 12,93 & 15,92 & 0,902 & 1,4 \\
\hline 4,13 & & 1,683996 & 0,002553 & 1,64 & 0,671 & 9,99 & 14,00 & 3,684 & 13,00 & 15,97 & 0,918 & 1,3 \\
\hline 4,20 & & 1,712538 & 0,003092 & 1,63 & 0,667 & 10,08 & 14,06 & 3,661 & 13,08 & 16,02 & 0,933 & 1,3 \\
\hline 4,27 & & 1,741081 & 0,003663 & 1,62 & 0,663 & 10,18 & 14,13 & 3,639 & 13,15 & 16,06 & 0,949 & 1,3 \\
\hline 4,34 & & 1,769623 & 0,004262 & 1,61 & 0,659 & 10,27 & 14,20 & 3,619 & 13,23 & 16,11 & 0,964 & 1,3 \\
\hline 4,41 & & 1,798165 & 0,004884 & 1,59 & 0,656 & 10,37 & 14,26 & 3,600 & 13,31 & 16,16 & 0,980 & 1,3 \\
\hline 4,48 & & 1,826707 & 0,005528 & 1,58 & 0,652 & 10,46 & 14,33 & 3,582 & 13,39 & 16,21 & 0,996 & 1,2 \\
\hline 4,55 & & 1,85525 & 0,006191 & 1,57 & 0,649 & 10,56 & 14,39 & 3,564 & 13,48 & 16,26 & 1,011 & 1,2 \\
\hline
\end{tabular}

The results of determining the working flow velocity, efficiency, and pump power are presented in a tabular form (Table 3)

Table 3. Calculation by formula 39 and determination of efficiency

Graphs are plotted to visualize the results and analyze the data obtained (Fig. 6,7)

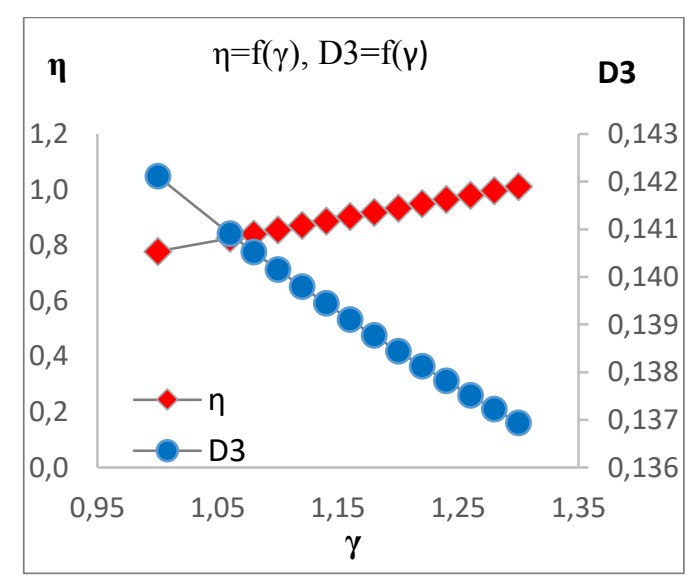

Fig. 6. The dependence of the efficiency and diameter $\mathrm{D}_{3}$ on $\gamma$

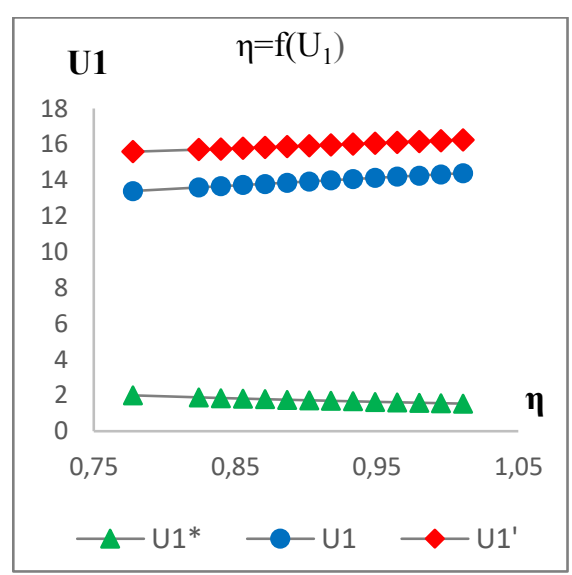

Fig. 7. The dependence of the efficiency on velocity $\mathrm{U}_{1}$ 


\section{Conclusions}

The effects of ejector geometries on ejector performance were studied. The ejector efficiencies were determined using the measured data. The solution of the practical problem showed that with an increase in the amount of solid particles, the efficiency of the ejector system also increases. The pressure loss affects the ejector work. The speed $U_{1}$ of the working flow calculated without taking into account losses is about 8 times less than the same speed calculated taking into account energy losses. The length of the general water pipe after the mixing chamber to the upper reservoir, when it is increased from $10 \mathrm{~m}$ to $100 \mathrm{~m}$, gives an increase in the required speed $\mathrm{U}_{1}$ by $15 \%$.

\section{References}

1. P. Kiselev, Gidravlica. Osnovi mehaniki jidkosti (1963)

2. Salienko S N 31.08.2018 Kompleksnoe ustrojstvo i sposob ispolzovaniya otrabotannoj vody, otlichayushchejsya po temperature $\mathrm{i} / \mathrm{ili}$ himicheskomu sostavu ot vody $\mathrm{v}$ estestvennom vodoeme, dlya zashchity ryb i predotvrashcheniyashugo- i ldoobrazovaniya. (Russian Federation. Certificate of state registration of a computer program) №RU 2665596 C1.

3. L.Volgina, V.Tarasov, T.Zommer Interne-vestnik VolgGASU, 3 (2012)

4. A. Zuykov, L. Volgina, Gidravlika 2 (2014)

5. YU. Bryanskaya, I. Markova, A. Ostyakova, Gidravlika vodnykh i vzvesenesushchikh potokov $v$ zhestkikh i deformiruyemykh granitsakh (2009)

6. B. Ksenofontov, Vodoochistka. Vodopodgotovka. Vodosnabzhenie, 8, 22-26 (2020)

7. V. Kirilenko, V. Tuchkov, Y. Kozhenov, Aktualnye problemy voenno-nauchnyh issledovanij, 11, 322-329 (2020)

8. V. Vancev, A. Kurnikov, Vestnik volzhskoj gosudarstvennoj akademii vodnogo transporta, 20, 19-26 (2006)

9. P. Kiselev, Osnovi teorii vodostruinih apparatov(ejectorov) (1979)

10. V. Aleksandrov, K. Klimovskij, Optimalnye ezhektory (teoriya i raschet) (2012)

11. D. Sun, Journal of Institute of Energy, 68, 65-79 (1995)

12. L. Berman, G. Efimochkin, Teploenergetika, 9, 9-14 (1963)

13. S. Xristianovich, O raschete ejectora (1944)

14. Y. Katto, Dynamics of Compressible Saturated Two-Phase Flow (Critical Flow-Sequel, and Flow in a Pipe) (1969)

15. E. Sokolov, N. Zinger, Strujnye apparaty 3 (1989)

16. V. Vancev, A. Kurnikov, Vestnik volzhskoj gosudarstvennoj akademii vodnogo transporta, 20, 19-26 (2006)

17. L. Berman, G. Efimochkin, Teploenergetika, 9, 9-14 (1963) 